\title{
Critical role of mass spectrometry proteomics in tear biomarker discovery for multifactorial ocular diseases (Review)
}

\author{
JESSICA YUEN WUEN MA $^{1^{*}}$, YING HON SZE ${ }^{1 *}$, JING FANG BIAN $^{1}$ and THOMAS CHUEN LAM ${ }^{1,2}$ \\ ${ }^{1}$ Laboratory of Experimental Optometry, Centre for Myopia Research, School of Optometry, \\ The Hong Kong Polytechnic University, Kowloon; ${ }^{2}$ Centre for Eye and Vision Research, Hong Kong, SAR, P.R. China
}

Received April 7, 2020; Accepted January 14, 2021

DOI: $10.3892 / \mathrm{ijmm} .2021 .4916$

\begin{abstract}
The tear film is a layer of body fluid that maintains the homeostasis of the ocular surface. The superior accessibility of tears and the presence of a high concentration of functional proteins make tears a potential medium for the discovery of non-invasive biomarkers in ocular diseases. Recent advances in mass spectrometry (MS) have enabled determination of an in-depth proteome profile, improved sensitivity, faster acquisition speed, proven variety of acquisition methods, and identification of disease biomarkers previously lacking in the field of ophthalmology. The use of MS allows efficient discovery of tear proteins, generation of reproducible results, and, more importantly, determines changes of protein quantity and post-translation modifications in microliter samples. The present review compared techniques for tear collection, sample preparation, and acquisition applied for the discovery of tear protein markers in normal subjects and multifactorial conditions, including dry eye syndrome, diabetic retinopathy, thyroid eye disease and primary open-angle glaucoma, which require an early diagnosis for treatment. It also summarized the contribution of MS to early discovery by means of disease-related protein markers in tear fluid and the potential for transformation of the tear MS-based proteome to antibody-based assay for future clinical application.
\end{abstract}

\section{Contents}

1. Introduction

2. Collection of tear fluid for clinical proteomics

Correspondence to: Dr Thomas Chuen Lam, Laboratory of Experimental Optometry, Centre for Myopia Research, School of Optometry, The Hong Kong Polytechnic University, 6 Yuk Choi Road, Kowloon, Hong Kong, SAR, P.R. China

E-mail: thomas.c.lam@polyu.edu.hk

${ }^{*}$ Contributed equally

Key words: tears, dry eye syndrome, diabetic retinopathy, thyroid eye disease, glaucoma, biomarker, mass spectrometry
3. MS proteomics approaches

4. Protein sample preparation for MS

5. Normal tear proteome in healthy ocular condition

6. Putative protein markers in tear fluid

7. Conclusions

\section{Introduction}

The tear film is a thin layer of body fluid secreted and produced by the meibomian gland, the main and accessory lacrimal glands, as well as the goblet cells in the conjunctiva (1). Tear fluid serves several functions: i) Lubricating the ocular surface; ii) providing nutrients to the corneal epithelium; iii) providing a moist and smooth surface for good vision; and iv) protecting the eyes against pathogens (2). The tear film is comprised of three layers: i) The lipid layer; ii) the aqueous layer; and ii) the innermost mucin layer with the aqueous and mucin layers forming a homogeneous layer $(3,4)$. Altogether, it consists of proteins (including enzymes), metabolites, electrolytes, lipids and glucose, and serves a critical function in the ocular system (5). The total tear protein concentration ranges from 3.5 to $9.5 \mathrm{mg} / \mathrm{ml}$ in basal tears and reflex tears, but is higher in newborns, ranging from 11 to $13 \mathrm{mg} / \mathrm{ml} \mathrm{(6),} \mathrm{and} \mathrm{is} \mathrm{increased} \mathrm{in} \mathrm{closed}$ eye conditions (6 to $18 \mathrm{mg} / \mathrm{ml}$ ) (7). It has been demonstrated that the proteins in the tear fluid play a significant role in regulating inflammatory responses (8), wound healing (9) and antibacterial protection (10). Mass spectrometry (MS) proteomic analysis not only provides a comprehensive characterization of tear fluid efficiently, but the multiplex nature of acquisition may also provide insights into the key mediators of biological responses and the status of the ocular surface (11). The high concentration of proteins and easy accessibility of tear fluid, compared with other ocular fluids, have made tears a sought-after target for proteomic studies in ophthalmology (12). However, the presence of abundant proteins, including lactotransferrin (LTF), secretory IgA, lipocalin-1 (LCN1) and lysozyme C (LYZ) detected using electrophoresis techniques $(13,14)$ and the small volume of tears has hampered comprehensive protein analysis of low abundant proteins. The advancement in nano-scale liquid chromatography coupled MS (nanoLC-MS) that offers extended dynamic range and sensitivity to identify $>1,000$ 
proteins, has opened up the possibility of tear biomarker research (15). With continued advances in techniques from sample preparation to MS acquisition, it is anticipated that the tear fluid will serve as an important matrix to develop molecular assays for ocular diseases and ophthalmology overall using the MS approach. Quantitative profiling and targeted MS methods have allowed multiplexed, reproducible screening of hundreds to thousands of proteins in a single, microliter volume (16) of tear fluid samples in early discovery, clinical trials and clinical proteomics application for the discovery of multifactorial ocular diseases.

\section{Collection of tear fluid for clinical proteomics}

Tear fluid can be obtained using several established collection methods, yet different sampling methods are known to affect the quality of tears samples and, consequently, the results of tear proteome analysis (17). The three most commonly adopted sampling methods for tear fluid are cellulose sponges, Schirmer's strips and capillary tubes. These sampling methods are non-invasive and do not require local anesthesia.

Cellulose sponges. A cellulose sponge may be used for tear collection by placing it into the lower conjunctival sac for $\sim 1$ min. It has been commonly adopted due to its high effectiveness in collecting tears, even from patients with low tear volume. This method is non-irritating and is generally well-tolerated by patients (18). Additionally, the sponge sampling method enables the standardization of the tear collection volume (19). Nevertheless, a variety of sponges and extraction buffers have been used in different studies, thus making it difficult to directly compare their results $(19,20)$. In addition, some cytokines, including interleukins and g-interferon, bind tightly to the sponge, making the recovery and extraction of these proteins more difficult (21).

Schirmer's strips. Schirmer's strips are used in the Schirmer's test for dry eye assessment (22). The strip is placed in the inferior conjunctival sac and left in place until it has been wetted to the control line. Later incubation in buffer solution to rehydrate the strip allows proteins or metabolites to be extracted for further molecular tests. This technique yields higher recovery of interleukins compared to samples collected with cellulose sponges (23) and improved protein identification than from tear fluid collected with a capillary tube (24). Although Schirmer's strips have been considered as a convenient and easy to perform method of tear collection, their use can cause strong irritation, leading to reflex tearing that results in unwanted dilution of tears (25). In addition, improper handling can also affect protein content (26). In particular, estimation of the tear protein loss during sample manipulation at the diffusion-based protein extraction stage ranged from $2 \%$ (LYZ) to $41.2 \%$ (mucin 4) (26).

Both the Schirmer's strip and cellulose sponge methods make use of absorptive materials that have contact with the conjunctiva, which can potentially damage the ocular surface. An increase in the number of certain proteins due to mechanical trauma of the conjunctiva has been reported $(27,28)$. Hence, extra care should be taken to minimize the trauma-induced stimulation of proteins during sample collection.

Capillary tube. To overcome the aforementioned drawbacks of absorptive materials, capillary tube or pipette sampling can be employed. The tear fluid is drawn from the inferior temporal tear meniscus near the external canthus of the eyes to a disposable borosilicate glass microcapillary tube by simple capillary force (29). Compared with the use of absorptive materials, this method is considered to be less invasive, to avoid reflex tearing, and to result in less protein disruption during the sample recovery process (30). However, it is time-consuming and requires precise handling, and may not be suitable for anxious or uncooperative patients and children (19). Improper handling of capillary tubes can induce reflex tears due to contact between the tube and the conjunctiva. In general, capillary tubes sampling is not always practicable and feasible in clinical studies that require reproducible data from large cohorts, particularly when children are involved (19). Furthermore, the collectible sample volume is limited. To overcome the limited tear volume of samples, pooling of tears from multiple subjects can be useful in research, but is undesirable in clinical studies as individual characteristics cannot be determined (31).

In brief, it is important to select the appropriate collection method for each specific study. For example, when a large sample volume is required, Schirmer's strips are preferable, but if dry eye patients with low tear menisci are involved, cellulose sponges are preferred $(32,33)$. Notably, the results of proteomics studies using different tear fluid collection methods are not directly comparable, and it is important to consider the potential impact of the collection method on protein concentration and expression.

\section{MS proteomics approaches}

Proteins are the key functional entities in the cell and arguably form the principle level of information required to understand any cellular function (34). Proteome refers to the entire protein complement expressed by the genome, while proteomics refers to the global analysis of protein mixtures (or their polypeptide components). Protein research and proteomics continue to develop and have become increasingly sophisticated. Proteomics research was initially qualitative, i.e., proteins were identified as being present in samples, providing the foundation for future research, but this alone was insufficient to characterize induced protein regulations and pathological conditions. For these purposes, proteomics analysis needed to be quantitative (35). Consequently, proteomic platforms with quantitative measurement of protein expression and protein post-translational modifications (PTMs) have been developed and become an integral and indispensable part of current proteomic studies (36). Discovery-based proteomics is typically conducted with a comparatively small set of samples to identify and quantify the differential expression of proteins. These proteins can then be verified and validated with a larger sample cohort to better account for biological variation, specificity and clinical longitudinal changes in expression. Data-dependent acquisition (DDA) was the first approach developed to survey abundant peptide masses in an unknown mixture, in which precursors were isolated and fragmented 
to generate a unique fingerprint spectrum of amino acid sequences for peptide identification in a high-resolution mass spectrometer. However, DDA has poor quantitative performance, because of the bias towards redundant proteins and poor reproducibility of signals and coverage of low abundant proteins (37). Data-independent acquisition (DIA) utilizes software-controlled mass isolation windows across the chromatogram, providing superior reproducibility and consistent acquisition ideal for quantitative results (38). In particular, the Sequential Window Acquisition of All Theoretical Mass Spectra (SWATH-MS) extended the data analysis concept of a targeted approach to achieve high-throughput DIA data extraction and statistical validation. SWATH-MS is one of the first methods to record all fragment ions of the detectable peptide precursors and highly multiplexed fragment ion maps included with low abundant peptides (39). DIA method, which relies on a high-quality mass spectral library generated from the DDA approach for peptide identification, remains the only label-free quantification method to survey and quantify the hundreds of thousands of proteins in complex biological samples without the prior knowledge of fragment mass transitions and peptide occurrences in the sample. Advances in proteomics were required and went hand in hand with intensive progress in computational interfaces, including databases, data processing algorithms, decoy peptides, accurate protein identification and data analysis of large proteome datasets (40). Isobaric tags for relative and absolute quantitation (iTRAQ) and Tandem mass tag (TMT) are isobaric labeling methods used in quantitative proteomics. These methods are based on the covalent labeling of the peptide with designated tags of reporter mass. Peptide samples are labeled and then pooled for preparation. This labeled approach allows multiplexed sampling and quantification of peptides that are ideal for pilot studies, as demonstrated in the analysis of tears in dry eye disease to quantify differential expressed proteins in a single MS acquisition (41).

Phosphorylation and glycosylation are common PTMs of proteins. A pilot study of phosphorylation enrichment using a titanium dioxide $\left(\mathrm{TiO}_{2}\right)$ column identified a total of 13 phosphoproteins in tear fluid, including mammaglobin-B (SCGB2A1), clusterin and protein UNQ773. Of note, phosphoproteins LCN1, immunoglobulin k constant (IGKC), polymeric immunoglobulin receptor (PIGR), lacritin (LACRT), cystatin S (CST4), proline-rich protein 4 (PRR4), deleted in malignant brain tumors 1 protein (DMBT1), immunoglobulin heavy constant a 1 (IGHA1), LYZ and immunoglobulin $\mathrm{J}$ chain (IGJ) had differentially expressed protein levels in ocular diseases, as described in a previously mentioned study (42). The use of PTMs as a biomarker in ocular diseases is limited, despite the high abundance of phosphoproteins reported in tear fluid (43). For example, glycosylation in the proline-rich protein family, and LACRT can be identified without an enrichment procedure (37). Methylation and acylation were observed in LCN1 and LYZ, however there was statistically significant difference of PTMs in dry eye disease (44). A total of $50 \mathrm{~N}$-linked glycans were identified in tears, five low abundance N-glycans (m/z 864.4, 945.5, 994.9, 1039.0 and 1112.0) and one O-glycan (m/z 665.2) were significantly different in patients with diabetes or diabetic retinopathy (45).

\section{Protein sample preparation for MS}

One-dimensional and two-dimensional gel electrophoreses (1DGE and 2DGE, respectively) were early proteomic tools used to separate, visualize and determine the size of proteins (46). MS was used to identify spots of abundant proteins and relative quantification of proteins. With this technique, proteins are separated according to isoelectric points (pI) through isoelectric focusing (IEF). In 1974, LTF and LYZ were found to be the major protein constituents in tear fluid (47). Using 1DGE, scientists found serum albumin (ALB) and transferrin were significantly elevated in the tear fluid of eyes even in mild cases of acute catarrhal conjunctivitis (48). Using 2DGE, scientists found lower abundance of proteins in human reflex tears, including CST4, cystatin SN and $\alpha$-2-glycoprotein, in addition to the previously reported LTF and LYZ (49), in particular, high expression of PRR4 in reflex tears (50). The fluorescence visualization of proteins in GE improved sensitivity compared with traditional Coomassie brilliant blue staining (51). However, irrespective of the staining method used, GE has a limited resolution of complex protein mixtures, low abundance proteins and co-appearing protein isoforms. It is also incompatible with hydrophobic proteins, for which it has limited access to various protein classes (52). Additionally, its limited dynamic range has hampered proteomic analysis of biofluids, such as human plasma, in which protein concentrations can differ up to 12 orders of magnitude (53). Unicellular organisms were used to benchmark 2DGE. However, detection of low abundance proteins remained a problem in this paradigm, despite the use of extended separation range and increased sample load, only 193 proteins were identified. This has demonstrated the limitations of the technique in a relatively simple model, and led to the conclusion that GE is not suitable for comprehensive global protein detection and quantitative profiling of protein networks (54). One-dimensional-liquid chromatography (1D-LC) offered a solution to the limitations of GE and has become increasingly popular over the past decade. Compared with GE-based proteomics, LC-based proteomics have improved reproducibility, streamlined peptide separation, increased sample throughput and dynamic range, and reduced sample consumption (55). These advances enabled the characterization of proteins in tissues (56), cells (57), plasma (58) and tears (59). The separation efficiency of LC is dependent on peak capacity, i.e., the maximum number of proteins that can be resolved in each separation time in a single sample acquisition (60). In human plasma, which has a particularly complex protein content, the highest achievable peak capacity of LC was reported to be 1,500 (61). It was also reported that the theoretical peak capacity of GE is three times lower than LC methods, due to its confined and definite retention volume (62). Consequentially, MS-based targeted proteomics have been rapidly adopted for quantifying proteins in complex clinical samples $(63,64)$. MS-based approaches perform particularly well with respect to assay sensitivity and specificity, when testing biomarker panels, rather than individual markers. Therefore, this technology has paved the way for multiparametric diagnostics that can significantly increase diagnostic accuracy (65). Currently, the only Food and Drug Administration (FDA)-approved, multi-parametric clinical 
test is designed to aid in the diagnosis of ovarian cancer. This test, which uses five serum proteins [CA125, transthyretin, apolipoprotein A-I, $\beta 2$-microglobulin (B2M) and transferrin], correctly predicted ovarian cancer in $94 \%$ of cases, which was significantly improved compared with the $66 \%$ rate observed with a single-parametric assay based on CA125 alone $(66,67)$. Therefore, MS-based proteomics is likely to become an important tool in the identification and application of multi-analyte biomarker panels, including the use of tear fluid samples for the diagnosis of ophthalmic diseases and conditions.

\section{Normal tear proteome in healthy ocular condition}

Under normal healthy ocular conditions, tear proteins are mainly released from the lacrimal gland (68), meibomian glands (69), goblet cells (70), and accessory lacrimal glands. Early discovery studies identified only 54 proteins in tears from subjects without eye diseases (37). The number of proteins identified increased notably to 491 in closed-eye tear fluid using hybrid linear ion trap-Fourier transform (LTQ-FT) and LTQ-Orbitrap mass spectrometers (71). The majority of the identified proteins were involved in the modulation of the immune system. They were responsible for carrying out immune, inflammatory responses as well as defense responses to pathogens. This study also focused on the identification of proteases and antioxidant enzymes. Among the 491 proteins identified, 64 were proteases or protease inhibitors, and 18 were antioxidant enzymes. These findings could explain the importance of tears in protecting the healthy ocular surface from noxious external stimulants and irritants. The results of studies of the proteome of human tears in healthy subjects are shown in Table I.

Tear proteome profiles of normal subjects have been the basic research standard for method assessment and development of the clinical use of tear proteomics. LTF, SCGB2A1, haptoglobin, $\alpha$-1-antitrypsin (SERPINA1), CST4, LCN1 and LACRT were found to be significantly upregulated in the tear fluid of female patients compared with male patients. A total of 253 proteins and 231 proteins were identified in the tears of male and female patients, respectively, using an electrophoresis method (72). The regulation of LCN1 in tear fluid was shown to be hormone-dependent in an experimental rabbit model, but the function of LCN1 in the tears of female patients remains unknown (73). Most upregulated proteins in the tear fluid of female patients were responsible for local immune defense responses. In-depth analysis with the use of fractionation, nanoscale reversed phase-liquid chromatography (nanoRP-LC), and TripleTOF $5600 \mathrm{MS}$ resulted in the report of a comprehensive human tear proteome, comprising the discovery of 1,543 proteins in normal healthy subjects (15). This number of proteins was significantly higher than other reports, so it should be noted that isoforms of the same protein were counted as separate proteins and only 714 proteins of the reported proteins were repeatable and reproducible in the triplicate analysis. Another study reported a total of 747 proteins in human tears (74), of which 595 were also reported by Zhou et al (15). Using an optimized extraction method and two-dimensional strong cation exchange-reversed phase (SCX-RP) with greater orthogonality of separation, Aass et al (75) reported 1,526 proteins in tear-fluid. We have converted the International Protein Index (IPI), GenInfo Identifier (GI) protein identification from the literature listed in Table I to a matched UniProt reviewed proteome for comparison. A total of 3,724 unique proteins (1\% False Discovery Rate in each study) were identified in tear fluid, with 1,397 (60\%) unique proteins only identified in Schirmer's strip samples, and $60(3 \%)$ unique proteins in tear samples collected with a capillary tube (Fig. 1). These independent studies had reported the most tear protein analyzed with LTQ-Orbitrap (Thermo Fisher Scientific, Inc.) and TripleTOF 5600 mass spectrometers (SCIEX). The combination of these studies is likely to increase the confidence of such protein identification. We propose that $435(19 \%)$ proteins commonly reported can be identified regardless of the tear fluid collection method and are the higher abundant, core protein in the composition of tear fluid. Comprehensive information of these 435 common proteins was derived from the UniProt database (https://www.uniprot.org) and is summarized in Table SI. Gene Ontology information on their biological processes and protein class was analyzed using the Omicsbean classification system (http://www.omicsbean.cn). The reported genes are categorized into 'Biological Process', 'Cell Component' and 'Molecular Function', and it was found that the enriched genes were involved in the top three pathways associated with 'vesicle-mediated transport', 'immune effector process' and 'exocytosis' (Fig. 2). These data were generated from a mixture of MS and vendors. Regardless of the MS system, common proteins are likely to be identified in tear fluid, but this will depend on the collection method. Several reports have stated that Orbitrap MS yields higher protein identifications compared with the TripleTOF MS (76-79).

\section{Putative protein markers in tear fluid}

Dry eye disease. Based on the definition and classification provided by the International Dry Eye Workshop in 2017 (80), dry eye disease is a multifactorial disease of the ocular surface characterized by a loss of homeostasis of the tear film that leads to tear film instability and hyperosmolarity, ocular surface inflammation, and neurosensory abnormalities and associated ocular symptoms (81). The two common types of dry eyes are known as the aqueous-deficient and evaporative dry eyes (82). Clinical diagnosis of dry eye diseases is based on questionnaires, Schirmer test, phenol red thread test, tear breakup time, corneal staining and tear osmolarity $(83,84)$. However, these assessments have shown poor reproducibility and large inter-test variability, as well as a poor correlation between the findings and subjective symptoms (85). Hence, an unmet need requires a reliable prognostic method when diagnosing dry eye diseases. Proteomic analysis of tear fluid has been increasingly used to identify biomarkers for ocular diseases.

Ocular surface inflammation is one of the major findings of patients with dry eye so several inflammatory proteins can act as possible biomarkers of dry eyes (86). It is reported that several inflammatory proteins are reported to be differentially expressed, including upregulated proteins of $\alpha$-enolase (ENO1), $\alpha$-1-acid glycoprotein 1 (ORM1), calgranulin A (S100A8), calgranulin B (S100A9), calvasculin (S100A4) and calgizzarin, and downregulated proteins of prolactin-inducible 





protein, LTF, LCN1 and LYZ (87). ORM1 protein promotes anti-inflammatory responses, whereas S100A8 and S100A9 proteins are pro-inflammatory proteins and are commonly found in the area of inflammation (88). Downregulated proteins LTF, LYZ and LCN1 are abundant proteins that protect against pathogens in tear fluid. The decreased expression of these proteins may explain why patients are prone to infectious ocular surface diseases (89). Notably, lipocalins promote the formation and maintenance of a compact and homogeneous outermost lipid layer of the tear film (90). Hence, decreased levels of lipocalins may lead to an unstable lipid layer, as well as an increased evaporation rate of the tear fluid. The levels of S100A8 and S100A9 are associated with the severity of meibomian gland dysfunction (MGD) and with symptoms of ocular redness and transient blurring in patients with dry eye (91). The upregulation of S100A8 and S100A9 occurs in response to the oxidative changes in redox regulation and inflammatory regulation (92). Significantly upregulated levels of ALB and downregulated lactase-phlorizin hydrolase, LCN1, SCGB2A1, and lipophilin A were reported in the evaporative dry eye disease (93). The increased level of ALB is an indication of passive exudation, i.e. a leaky blood-eye barrier in conjunctival vessels (94).

Another previous study reported the differential expression of PRR4, zymogen granule protein 16 homolog B (ZG16B), DMBT1, LACRT, opiorphin prepropeptide (PROL1), aldehyde dehydrogenase dimeric NADP-preferring (ALDH3A1), phosphatidylethanolamine-binding protein 1 , serotransferrin (TF), together with S100A8, S100A9, SCGB2A1, ENO1 and ORM1 that were previously reported in the literature (95). The increased expression of PRR4 and ZG16B in dry eye disease may indicate an impaired neurological process of the lacrimal gland. Downregulation of DMBT1 impairs epithelial differentiation and cellular defense mechanisms, whereas the reduction of LACRT may account for the reduced tears secretion in patients with dry eye (96). The reduction of PROL1 affects the paracrine or autocrine pathway of the lacrimal system (97). The ALDH3A1 protein protects against the oxidative stress of toxic radicals on the corneal surface (98). The upregulation of TF protein was only identified in the aqueous deficient type of dry eye (95). A previous study demonstrated the complex molecular difference between dry eye disease and MGD. Thioredoxin, Ig $\gamma-1$, membrane-associated phospholipase A2, SERPINA1 and antileukoproteinase (SLPI) were found to be upregulated in patients with dry eye, yet these proteins were downregulated in MGD. In addition, lactoperoxidase (LPO) was significantly downregulated in dry eye disease and upregulated in MGD (99). The upregulation of these proteins suggests enhanced immune, host-defense and proteolytic responses in aqueous-deficient dry eye disease, whereas the contrary may be the case in the evaporative dry eye caused by MGD. Furthermore, the higher level of hyperosmolarity in patients with MGD may lead to an increased expression of oxidative stress-associated LPO protein in MGD when compared with patients with dry eye. The differential expression of proteins between MGD and dry eye suggest different regulatory processes. S100A8, S100A9 and ORM1 were identified as differentially expressed in all the dry eye studies reported in the present review (Table II). Hence, these proteins may

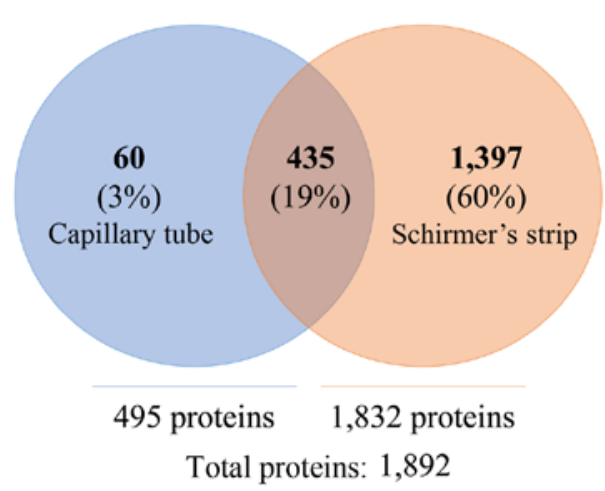

Figure 1. Venn diagram of the number of proteins (UniProt reviewed protein) collected with capillary tube or Schirmer strips in Table I. A total of 2,327 unique proteins (1\% False Discovery Rate) were reported in tear fluid using mass spectrometry techniques. Of these, 495 and 1,832 unique proteins were identified in tears collected with a capillary tube and Schirmer's strip, respectively.

serve as biomarkers of dry eye disease, in addition to the established biomarker matrix metalloproteinase-9 (MMP-9) that is already being employed in the diagnosis of dry eye disease (100). Although anterior ocular inflammation is a typical feature of Sjögren syndrome, it is considered to be a systemic autoimmune disease with some distinct clinical presentation (101). Different from physiological dry eyes, aqueous-deficient and evaporative dry eyes, which could be clinically difficult to differentiate using routine clinical assessments. It was recently found that the elevated MMP-9 protein biomarker is non-specific and difficult to distinguish Sjögren syndrome from typical dry eye diseases (102). MS-based proteomics approaches enabled the discovery of the upregulation of other pro-inflammatory proteins, including LIM domain only protein 7, E3 ubiquitin-protein ligase and Copine-1, as well as in the involvement of TNF- $\alpha$ signaling $(103,104)$, which suggested the possibility that specific molecular biomarkers may be developed for more specific clinical diagnosis.

These studies have provided preliminary data on protein biomarkers in tear fluid using MS techniques. However, there are several limitations of using tear proteomics to make a diagnosis of dry eyes. The tear sampling methods and ways of sample manipulation differ among the reported studies; hence, a direct comparison between these studies may not be appropriate. To achieve comparable results, standardization of sampling methods and sample manipulation protocols are required in the future. Additionally, S100A8 and S100A9, which were differentially expressed in all of the studies, were also reported in patients with glaucoma (Table II), indicating that these inflammatory proteins are not differentially expressed uniquely in patients with dry eye (105). In summary, several potential biomarkers have been identified in patients with dry eyes, but whether a diagnosis of dry eyes can be based on tear proteomics remains to be determined and defined. A signature panel of tear fluid biomarkers is needed to address overlap with other conditions to increase the specificity of tear fluid protein markers for the diagnosis of dry eye diseases.

Diabetic retinopathy. Diabetic retinopathy is a common complication of diabetes mellitus (DM). The condition is asymptomatic in the early stages of disease development, yet it 

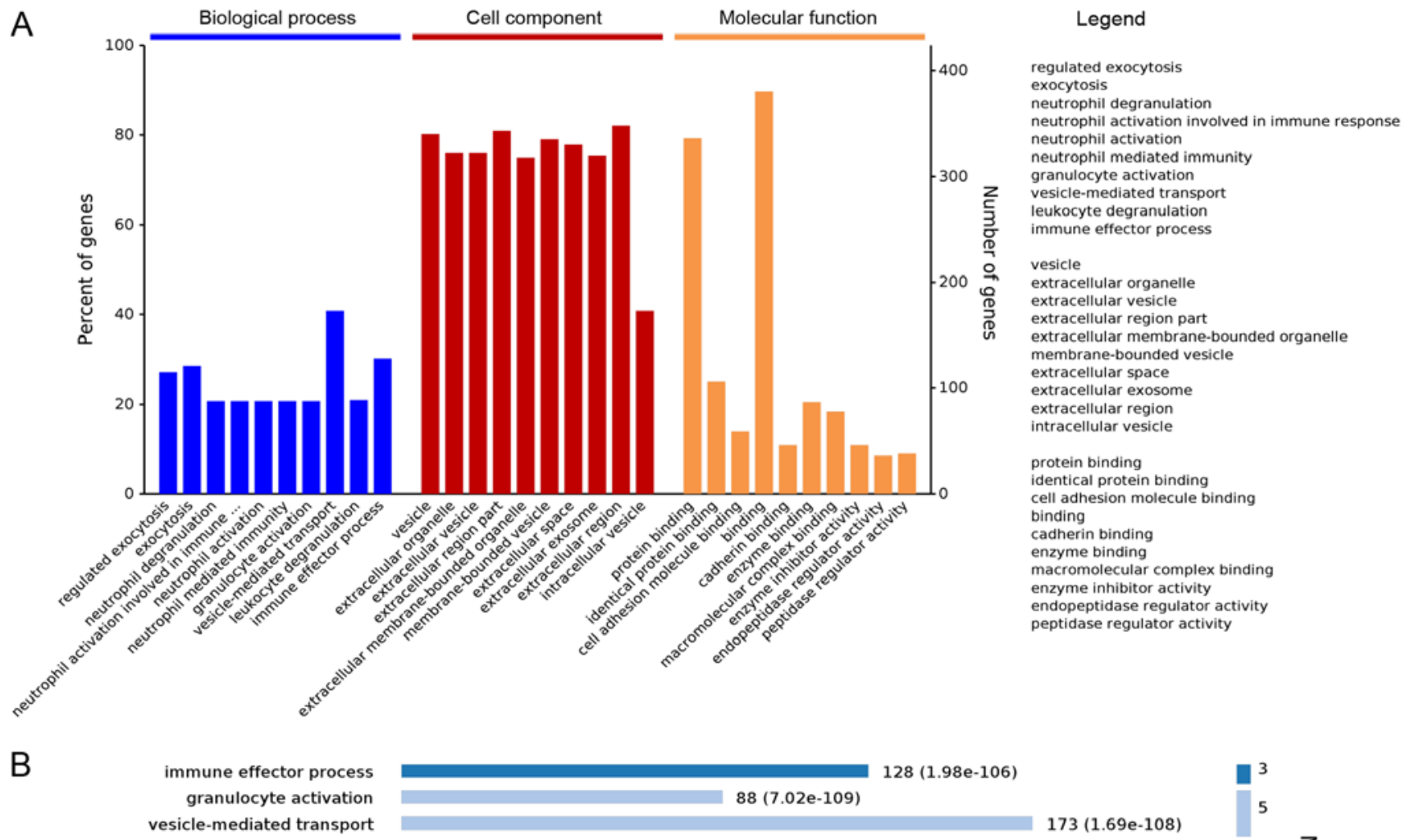

neutrophil activation involved in immune... neutrophil activation neutrophil mediated immunity neutrophil degranulation exocytosis regulated exocytosis leukocyte degranulation
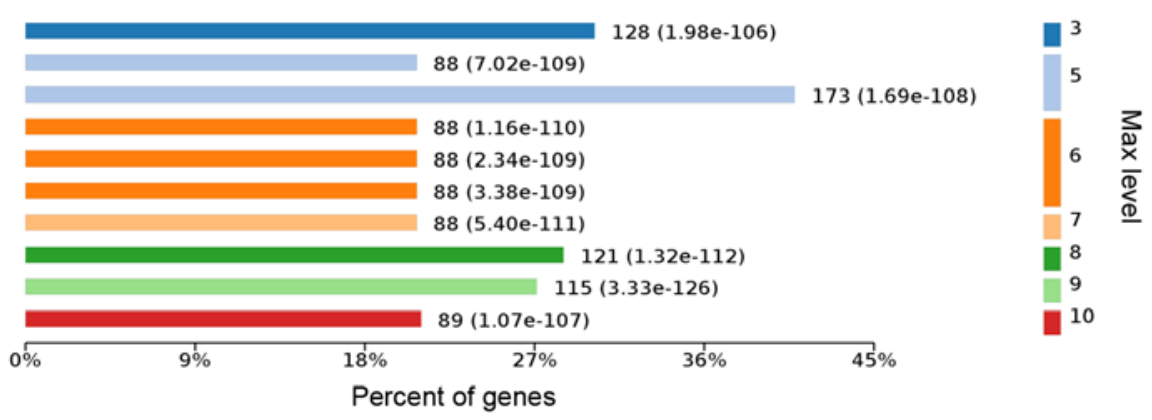

Figure 2. Omicsbean Gene Ontology analysis of the 435 common tear proteins. (A) The bars indicate the proportion of converted gene represented per 'Biological Process', 'Cell Component' and 'Molecular Function'. (B) Top 10 enriched significant pathways with the percentage of genes under each pathway of the 435 common proteins.

can cause irreversible blindness in its final stages. Tear composition can be affected by DM, although the tear film is not in direct contact with the retina (106). Hence, tear proteins may act as biomarkers for the screening of diabetic retinopathy. The relative abundance of LACRT, Ig lambda chain $\mathrm{C}$ region (LAC), LTF, LYZ, LCN1 and SCGB2A1 proteins were upregulated in patients with proliferative diabetic retinopathy (PDR) compared with non-PDR and healthy subjects (107). The upregulated expression levels of LTF, LAC and LACRT may reflect an increased inflammatory response, potentially caused by macular edema, vascular abnormalities, the proliferation of the ocular cells, and an indicator of the pro-proliferative environment that is essential for the progression of diabetic retinopathy (108).

Thyroid eye disease. Thyroid-associated orbitopathy (TAO) is an autoimmune disorder that affects the orbit. TAO is characterized by enlarged extraocular muscles, orbital tissue and inflammatory changes, including upper eyelid retraction, proptosis and erythema of the conjunctiva (109). There are two phases of TAO: The inflammatory phase, which requires anti-inflammatory treatment, and a later less active stage (110). The clinical diagnosis, assessment and management of the disease are based on the Clinical Activity Score (CAS) (111). However, disease onset, prognosis and time course of TAO remain unclear. TAO mainly affects the extraocular muscles, eyelid and orbital tissue. These surrounding damaged tissues may release different proteins into tears or by passive transport from blood; therefore, tears may contain potential protein markers for the diagnosis of TAO (112). However, the composition of tears collected from patients with TAO need to be analyzed carefully as it may contain certain inflammatory proteins that are associated with exposure keratitis, which is a common complication of TAO (113).

In one previous study, the expression of three proteins was modulated in patients with TAO (114). LYZ was found to be upregulated, whereas PRP4 and B2M were downregulated in patients with TAO. LYZ is a proteolytic protein that is important in the immune response (115) and increased LYZ is found in patients with autoimmune diseases (116). The increase of LYZ may suggest increased inflammatory responses of the lacrimal gland. Lacrimal PRP4 can regulate the microflora of the eye to protect the ocular surface (117). The inflammatory processes of the orbit in TAO may decrease the lacrimal expression of PRP4. It has been demonstrated that increased 


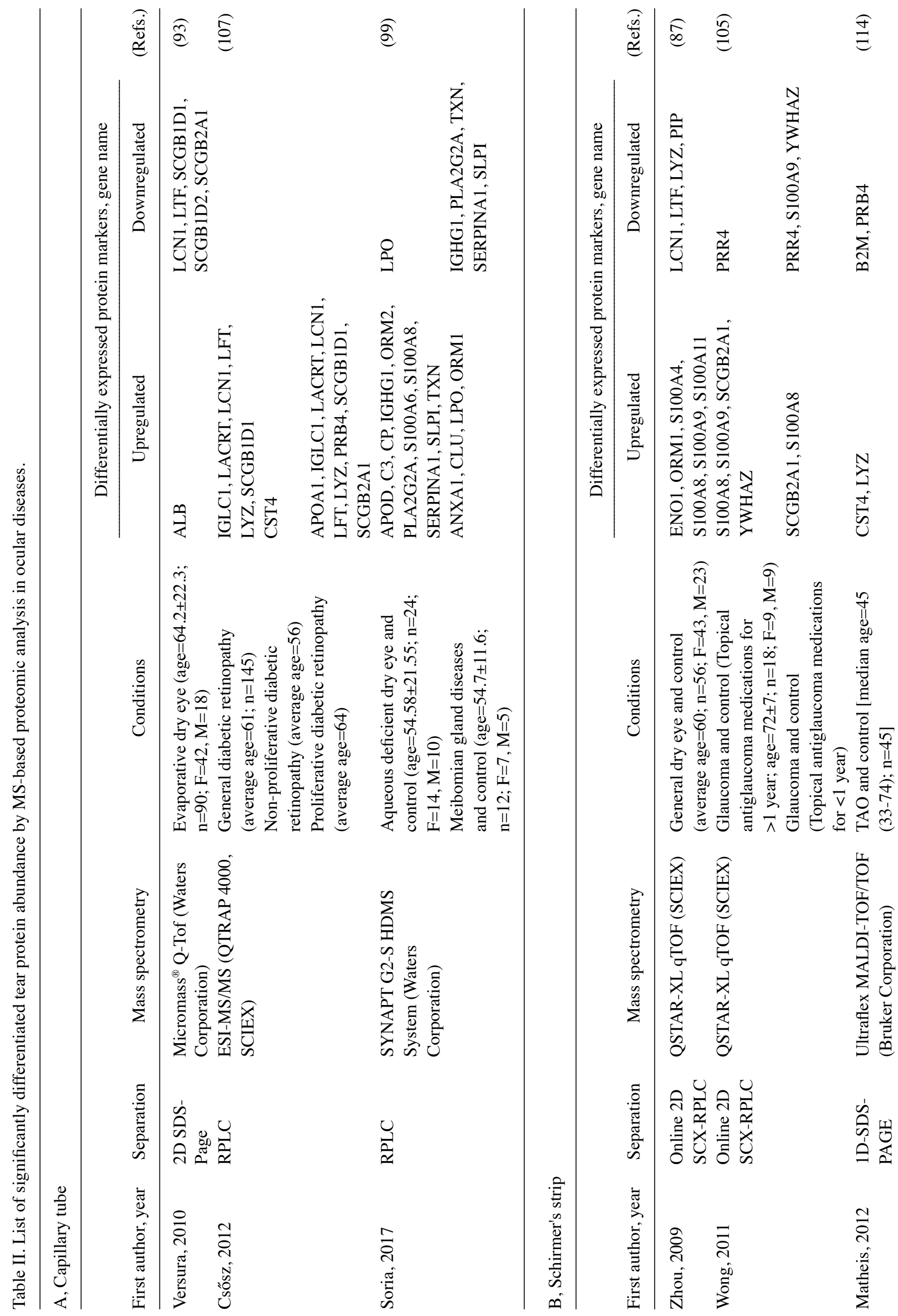




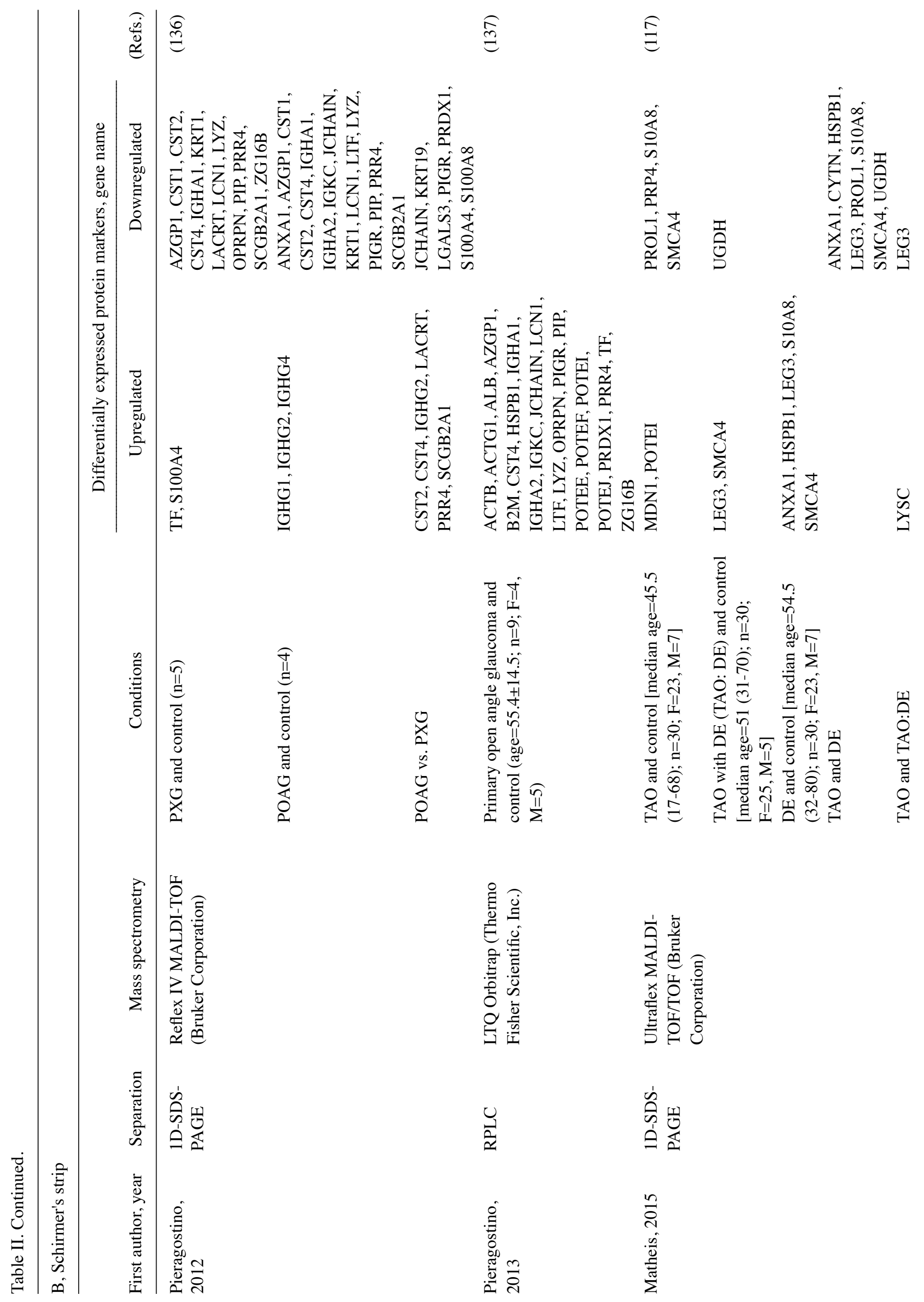




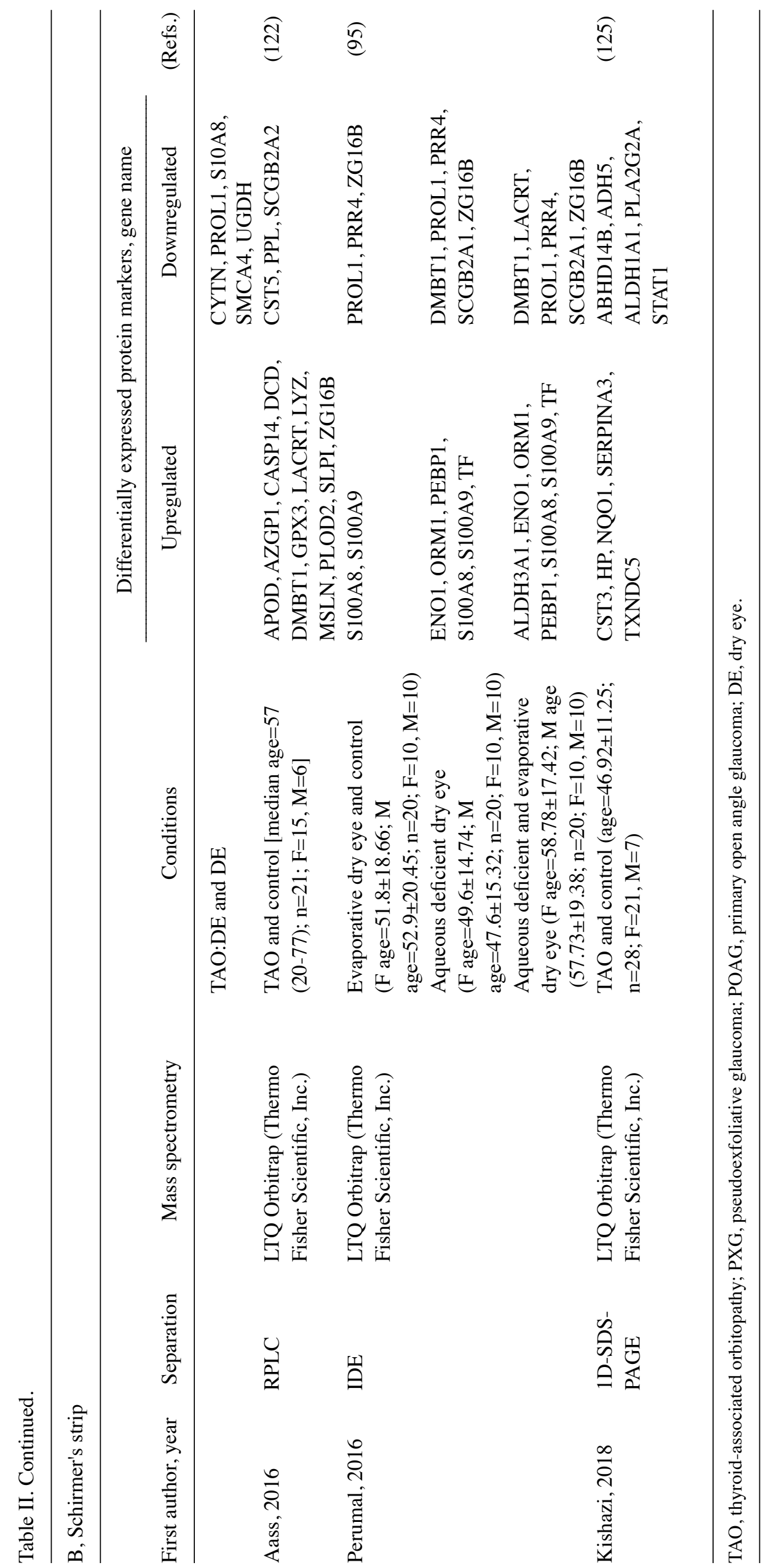


levels of inflammation and higher CAS values are associated with lower levels of PRP4, indicating the progressive nature of the inflammatory lacrimal gland dysfunction in patients with TAO (114). B2M belongs to the major histocompatibility complex class I molecules and also plays an important role in immune responses (118). The downregulation of B2M may reflect altered immune function in this auto-immune disease.

Patients with TAO can have signs and symptoms similar to dry eye syndrome, which can result in delayed diagnosis of TAO (117). In comparison to normal subjects, transcription activator BRG1 (SMCA4), PROL1, PPR4 and S100A8 proteins were downregulated, whereas midasin, POTE ankyrin domain family member I and LYZ proteins were upregulated in patients with TAO (117). In comparison to patients with dry eye, UDP-glucose 6-dehydrogenase (UGDH), annexin A1, cystatin-C (CST3), heat shock protein $\beta 1$ (HSPB1), galectin-1, PROL1, S100A8 and SMCA4 proteins were downregulated in patients with TAO (117). The apoptosis of lacrimal cells can cause the downregulation of PROL1 and PRR4 proteins, the protective enzymes secreted by the lacrimal acinar cells in TAO (119). The damage to the lacrimal cells can reduce the number of cystatin proteins, which perform protective function in the tears (120). UGDH protein is responsible for the indirect production of the glycosaminoglycans that are expressed in fibroblasts in the active phase of TAO (121). The downregulation of UGDH protein can be explained by the fact that the majority of the patients involved in this study were in advanced and inactive stages of TAO. A similar study reported 12 upregulated proteins in patients with TAO, including caspase-14, SLPI, dermcidin (DCD), procollagen-lysine 2-oxoglutarate 5-dioxygenase 2, mesothelin, apolipoprotein $\mathrm{D}$, glutathione peroxidase 3 , zinc- $\alpha$-2-glycoprotein 1 , DMBT1, ZG16B and LACRT (122). The overexpression of CASP14, SLPI and LYZ proteins may represent the inflammatory responses of the ocular surface, orbital tissue or lacrimal gland. However, the exact function of CASP14 in tear fluid remains unclear. DCD protein has anti-microbial properties and has been detected in conjunctival cells (123). Increased amounts of DCD protein suggest more bulbar conjunctiva inflammation in patients with TAO (124). In a more recent study, retinal dehydrogenase 1, SERPINA3 and CST3 proteins were found to be upregulated in tear fluid obtained from patients with TAO (125). CST3 protein is a cysteine protease inhibitor that is concentrated and expressed in the retinal pigment epithelium (126). The concentration of CST3 protein in the blood is associated with thyroid functioning (127). The downregulation of retinol dehydrogenase 11 protein may result in reduced synthesis of retinoic acid, hence, affecting the visual pigment and leading to vision loss (128). Increased expression of SERPINA3, a protein responsible for mediating inflammatory responses, may reflect the increased level of eye inflammation in TAO, which is an autoimmune disease with orbital inflammatory responses. Different biomarkers for TAO have been identified across different studies (Table II), further validation should be carried out to confirm potential biomarkers and these biomarkers should be analyzed according to the severity or different stages of TAO.

Primary open-angle glaucoma (POAG). Glaucoma is a progressive neurodegenerative disease that causes optic nerve head damage, retinal nerve fiber layer defects, and is associated with the loss of the visual field (129). It is one of the main causes of blindness worldwide (130). The underlying mechanism of glaucoma remains unclear, and the clinical diagnosis of glaucoma relies on several assessments, including tonometry, dilated fundus image examination, visual field test, gonioscopy and pachymetry (129). Visual field impairment is a cause of irreversible damage to retinal ganglion cells (131). Tear fluid proteomic profiling may provide novel insights into the understanding and diagnosis of glaucoma and may serve to monitor therapy, including the side effects of medication. POAG is the most common subty pe of open-angle glaucoma in the European population (132). The damaged trabecular meshwork and modification of the aqueous humor leads to an impaired drainage system. The accumulation of fluid increases the intraocular pressure (IOP) of the eye (133). Pseudoexfoliative glaucoma (PXG) is another subtype of POAG and is characterized by the production and accumulation of abnormally high concentration of fibrillar and proteinaceous substances in the anterior segment of the eyes (134). These substances can block the ocular drainage system and thus increase the IOP of the eye, one of the risk factors of glaucoma (135). A total of 23 differentially expressed proteins have been reported in POAG and PXG. Cystatin-SA, CST4, SCGB2A1, Ig $\gamma$-2 chain C region and PRR4 proteins were found to be upregulated in POAG, but not PXG. Peroxiredoxin-1, IGJ, galectin-3, PIGR, keratin type I cytoskeletal 19, S100A4, S100A8 and LACRT were found to be downregulated in POAG compared with PXG samples. More importantly, keratin type I cytoskeletal 10 and apolipoprotein A-II proteins are unique to POAG tear fluid (136). B2M, HSPB1, IGHA1, immunoglobulin heavy constant $\alpha 2$, IGJ, IGKC, LTF, LYZ, PIGR, TF and ALB proteins were also upregulated in patients with POAG (136). The modulation of these proteins between treated and untreated POAG groups indicated that PGA works effectively via the anti-inflammatory mechanism. Proteomics was applied to monitor patients chronically treated with topical antiglaucoma medications, finding that SCGB2A1, S100A8, S100A9 and 14-3-3 $\zeta / \delta$ proteins were upregulated, whereas PRR4 was downregulated in patients with glaucoma treated with IOP lowering medication (105). The results indicated that the use of topical antiglaucoma medications for $>1$ year affects the ocular surface by inducing inflammatory responses. The tear fluid proteome of the medically treated patients with glaucoma and patients with dry eyes compared with normal control subjects have shown upregulation of S100A8 and S100A9 proteins in both glaucoma and dry eye patients. Proteins expressed in medi-

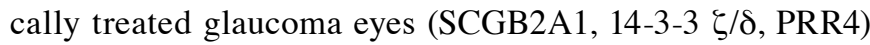
or dry eyes (ENO1, S100A4) did not exhibit a common expression pattern between conditions (137). These results suggested that distinct, yet complex mechanisms lead to different inflammatory responses in ocular diseases that can be distinguished using MS-based proteomic techniques.

\section{Conclusions}

The present review provided a brief introduction to the development of proteomics platforms for tear proteome studies. The proteome identified in normal tear fluid and its expression in dry eye syndrome, diabetic retinopathy, thyroid eye disease 
and POAG were summarized. MS-based methods have evolved rapidly with technological advances in high-resolution mass spectrometers and data analysis tools for a variety of discovery-based experiments, resulting in ever-larger proteomic datasets in tear fluid. With respect to accurate quantitative proteomics, DIA and labeled tags offer consistent quantification of proteins in disease conditions for both pilot and large cohort studies. MS technology continues to improve and has enabled in-depth protein profiling, reliable quantification with superior flexibility for assay development, and remains the only antibody-free approach for protein analysis in biological samples. The consistent results of analyzing the microliter volumes of tear fluid or differentiated proteins has demonstrated the potential development of assays for ocular diseases and ophthalmology overall using a variety of MS approaches. For future approved molecular diagnostics, a custom-made antibody-based assay or point of care diagnostic molecular kit could be developed to target specific proteins, taking full advantage of established, lower-cost, and ease of use into clinical use.

\section{Acknowledgements}

The authors would like to thank Dr Maureen Boost (Hong Kong Polytechnic University, Hong Kong, China) for her diligent proofreading of the article.

\section{Funding}

This work was supported by a Ph.D. student scholarship (grant no. RKTA) of The Hong Kong Polytechnic University.

\section{Availability of data and materials}

The datasets used and/or analyzed during the current study are available from the corresponding author on reasonable request.

\section{Authors' contributions}

JYWM and YHS drafted the manuscript. JFB edited and formatted the manuscript. TCL conceived the idea, proofread the manuscript, and provided financial support. All authors read and approved the final manuscript.

\section{Ethics approval and consent to participate}

Not applicable.

\section{Patient consent for publication}

Not applicable.

\section{Competing interests}

The authors declare that they have no competing interests.

\section{References}

1. Dogru M, Okada N, Asano-Kato N, Tanaka M, Igarashi A, Takano Y, Fukagawa K, Shimazaki J, Tsubota K and Fujishima H: Atopic ocular surface disease: Implications on tear function and ocular surface mucins. Cornea 24 (8 Suppl): S18-S23, 2005.
2. Gipson IK: The ocular surface: The challenge to enable and protect vision: The Friedenwald lecture. Invest Ophthalmol Vis Sci 48: 4390-4398, 2007.

3. Miano F, Mazzone M, Giannetto A, Enea V, Mc Cauley P, Bailey A and Winlove PC: Interface properties of simplified tear-like fluids in relation to lipid and aqueous layers composition. Adv Exp Med Biol 506: 405-417, 2002.

4. King-Smith PE, Bailey MD and Braun RJ: Four characteristics and a model of an effective tear film lipid layer (TFLL). Ocul Surf 11: 236-245, 2013.

5. Kijlstra A and Kuizenga A: Analysis and function of the human tear proteins. Adv Exp Med Biol 350: 299-308, 1994.

6. Esmaeelpour M, Watts PO, Boulton ME, Cai J and Murphy PJ: Tear film volume and protein analysis in full-term newborn infants. Cornea 30: 400-404, 2011.

7. Sack RA, Sathe S and Beaton A: Tear turnover and immune and inflammatory processes in the open-eye and closed-eye environments: Relationship to extended wear contact lens use. Eye Contact Lens 29 (Suppl 1): S80-S84, S192-S194, 2003.

8. Stern ME, Schaumburg CS, Dana R, Calonge M, Niederkorn JY and Pflugfelder SC: Autoimmunity at the ocular surface: Pathogenesis and regulation. Mucosal Immunol 3: 425-442, 2010.

9. Schicht M, Garreis F, Hartjen N, Beileke S, Jacobi C, Sahin A, Holland D, Schröder H, Hammer CM, Paulsen F and Bräuer L: SFTA3-a novel surfactant protein of the ocular surface and its role in corneal wound healing and tear film surface tension. Sci Rep 8: 9791, 2018.

10. Kwong MS, Evans DJ, Ni M, Cowell BA and Fleiszig SM: Human tear fluid protects against Pseudomonas aeruginosa keratitis in a murine experimental model. Infect Immun 75: 2325-2332, 2007.

11. Zhou L and Beuerman RW: The power of tears: How tear proteomics research could revolutionize the clinic. Expert Rev Proteomics 14: 189-191, 2017.

12. Hagan S, Martin E and Enriquez-de-Salamanca A: Tear fluid biomarkers in ocular and systemic disease: Potential use for predictive, preventive and personalised medicine. EPMA J 7: 15 , 2016.

13. Gachon AM and Lacazette E: Tear lipocalin and the eye's front line of defence. Br J Ophthalmol 82: 453-455, 1998.

14. Kuizenga A, van Haeringen NJ and Kijlstra A: Identification of lectin binding proteins in human tears. Invest Ophthalmol Vis Sci 32: 3277-3284, 1991 .

15. Zhou L, Zhao SZ, Koh SK, Chen L, Vaz C, Tanavde V, Li XR and Beuerman RW: In-depth analysis of the human tear proteome. J Proteomics 75: 3877-3885, 2012.

16. Mishima S, Gasset A, Klyce SD Jr and Baum JL: Determination of tear volume and tear flow. Invest Ophthalmol 5: 264-276, 1966.

17. Rentka A, Koroskenyi K, Harsfalvi J, Szekanecz Z, Szucs G, Szodoray P and Kemeny-Beke A: Evaluation of commonly used tear sampling methods and their relevance in subsequent biochemical analysis. Ann Clin Biochem 54: 521-529, 2017.

18. Esmaeelpour M, Cai J, Watts P, Boulton M and Murphy PJ: Tear sample collection using cellulose acetate absorbent filters. Ophthalmic Physiol Opt 28: 577-583, 2008.

19. Inic-Kanada A, Nussbaumer A, Montanaro J, Belij S, Schlacher S, Stein E, Bintner N, Merio M, Zlabinger GJ and Barisani-Asenbauer T: Comparison of ophthalmic sponges and extraction buffers for quantifying cytokine profiles in tears using Luminex technology. Mol Vis 18: 2717-2725, 2012.

20. López-Cisternas J, Castillo-Diaz J, Traipe-Castro L and López-Solis RO: Use of polyurethane minisponges to collect human tear fluid. Cornea 25: 312-318, 2006

21. Rohan LC, Edwards RP, Kelly LA, Colenello KA, Bowman FP and Crowley-Nowick PA: Optimization of the weck-Cel collection method for quantitation of cytokines in mucosal secretions. Clin Diagn Lab Immunol 7: 45-48, 2000.

22. Posa A, Bräuer L, Schicht M, Garreis F, Beileke S and Paulsen F: Schirmer strip vs capillary tube method: Non-invasive methods of obtaining proteins from tear fluid. Ann Anat 195: 137-142, 2013.

23. VanDerMeid KR, Su SP, Krenzer KL, Ward KW and Zhang JZ: A method to extract cytokines and matrix metalloproteinases from Schirmer strips and analyze using Luminex. Mol Vis 17: 1056-1063, 2011.

24. Nättinen J, Aapola U, Jylhä A, Vaajanen A and Uusitalo H: Comparison of capillary and Schirmer strip tear fluid sampling methods using SWATH-MS proteomics approach. Transl Vis Sci Technol 9: 16, 2020 
25. Stuchell RN, Feldman JJ, Farris RL and Mandel ID: The effect of collection technique on tear composition. Invest Ophthalmol Vis Sci 25: 374-377, 1984.

26. Denisin AK, Karns K and Herr AE: Post-collection processing of Schirmer strip-collected human tear fluid impacts protein content. Analyst 137: 5088-5096, 2012.

27. van Haeringen NJ and Glasius E: The origin of some enzymes in tear fluid, determined by comparative investigation with two collection methods. Exp Eye Res 22: 267-272, 1976.

28. Zhou L and Beuerman RW: Tear analysis in ocular surface diseases. Prog Retin Eye Res 31: 527-550, 2012.

29. Castelli S, Arasi S, Pawankar R and Matricardi PM: Collection of nasal secretions and tears and their use in allergology. Curr Opin Allergy Clin Immunol 18: 1-9, 2018.

30. Leonardi A: Allergy and allergic mediators in tears. Exp Eye Res 117: 106-117, 2013.

31. Green-Church KB, Nichols KK, Kleinholz NM, Zhang L and Nichols JJ: Investigation of the human tear film proteome using multiple proteomic approaches. Mol Vis 14: 456-470, 2008

32. Kojima T, Dogru M, Kawashima M, Nakamura $S$ and Tsubota $K$ : Advances in the diagnosis and treatment of dry eye. Prog Retin Eye Res: Jan 29, 2020 (Epub ahead of print). doi: 10.1016/j preteyeres.2020.100842.

33. Mainstone JC, Bruce AS and Golding TR: Tear meniscus measurement in the diagnosis of dry eye. Curr Eye Res 15: 653-661, 1996.

34. Altelaar AF, Munoz J and Heck AJ: Next-generation proteomics: Towards an integrative view of proteome dynamics. Nat Rev Genet 14: 35-48, 2013.

35. Schubert OT, Röst HL, Collins BC, Rosenberger G and Aebersold R: Quantitative proteomics: Challenges and opportunities in basic and applied research. Nat Protoc 12: 1289-1294, 2017

36. Zhao $\mathrm{Y}$ and Jensen ON: Modification-specific proteomics: Strategies for characterization of post-translational modifications using enrichment techniques. Proteomics 9: 4632-4641, 2009.

37. Li N, Wang N, Zheng J, Liu XM, Lever OW, Erickson PM and Li L: Characterization of human tear proteome using multiple proteomic analysis techniques. J Proteome Res 4: 2052-2061, 2005.

38. Gillet LC, Navarro P, Tate S, Röst H, Selevsek N, Reiter L, Bonner R and Aebersold R: Targeted data extraction of the MS/MS spectra generated by data-independent acquisition: A new concept for consistent and accurate proteome analysis. Mol Cell Proteomics 11: O111.016717, 2012

39. Collins BC, Hunter CL, Liu Y, Schilling B, Rosenberger G, Bader SL, Chan DW, Gibson BW, Gingras AC, Held JM, et al: Multi-laboratory assessment of reproducibility, qualitative and quantitative performance of SWATH-mass spectrometry. Nat Commun 8: 291, 2017.

40. Molloy MP: The challenge of industrializing proteomics. Nat Biotechnol 21: 597, 2003.

41. Srinivasan S, Thangavelu M,Zhang L, Green KB and Nichols KK iTRAQ quantitative proteomics in the analysis of tears in dry eye patients. Invest Ophthalmol Vis Sci 53: 5052-5059, 2012.

42. Zhao Z, Liu J, Wasinger VC, Malouf T, Nguyen-Khuong T, Walsh B and Willcox MD: Tear lipocalin is the predominant phosphoprotein in human tear fluid. Exp Eye Res 90: 344-349, 2010.

43. You J, Fitzgerald A, Cozzi PJ, Zhao Z, Graham P, Russell PJ, WalshBJ,Willcox M,ZhongL, Wasinger V andLi Y:Post-translation modification of proteins in tears. Electrophoresis 31: 1853-1861, 2010.

44. Huang Z, Du CX and Pan XD: The use of in-strip digestion for fast proteomic analysis on tear fluid from dry eye patients. PLoS One 13: e0200702, 2018.

45. Nguyen-Khuong T, Everest-Dass AV, Kautto L, Zhao Z, Willcox MD and Packer NH: Glycomic characterization of basal tears and changes with diabetes and diabetic retinopathy. Glycobiology 25: 269-283, 2015.

46. Magdeldin S, Enany S, Yoshida Y, Xu B, Zhang Y, Zureena Z Lokamani I, Yaoita E and Yamamoto T: Basics and recent advances of two dimensional-polyacrylamide gel electrophoresis. Clin Proteomics 11: 16, 2014.

47. Broekhuyse RM: Tear lactoferrin: A bacteriostatic and complexing protein. Invest Ophthalmol 13: 550-554, 1974.

48. Berta A: A polyacrylamide-gel electrophoretic study of human tear proteins. Graefes Arch Clin Exp Ophthalmol 219: 95-99, 1982.

49. Molloy MP, Bolis S, Herbert BR, Ou K, Tyler MI, van Dyk DD, Willcox MD, Gooley AA, Williams KL, Morris CA and Walsh BJ Establishment of the human reflex tear two-dimensional polyacrylamide gel electrophoresis reference map: New proteins of potential diagnostic value. Electrophoresis 18: 2811-2815, 1997.
50. Perumal N, Funke S, Wolters D, Pfeiffer N and Grus FH: Characterization of human reflex tear proteome reveals high expression of lacrimal proline-rich protein 4 (PRR4). Proteomics 15: 3370-3381, 2015.

51. Ladner CL, Yang J, Turner RJ and Edwards RA: Visible fluorescent detection of proteins in polyacrylamide gels without staining. Anal Biochem 326: 13-20, 2004.

52. Williams JG and Gratzer WB: Limitations of the detergent-polyacrylamide gel electrophoresis method for molecular weight determination of proteins. J Chromatogr 57: 121-125, 1971.

53. Corthals GL, Wasinger VC, Hochstrasser DF and Sanchez JC: The dynamic range of protein expression: A challenge for proteomic research. Electrophoresis 21: 1104-1115, 2000.

54. Gygi SP, Corthals GL, Zhang Y, Rochon Y and Aebersold R: Evaluation of two-dimensional gel electrophoresis-based proteome analysis technology. Proc Natl Acad Sci USA 97: 9390-9395, 2000

55. Shi Y, Xiang R, Horvath $\mathrm{C}$ and Wilkins JA: The role of liquid chromatography in proteomics. J Chromatogr A 1053: 27-36, 2004.

56. Uhlén M, Fagerberg L, Hallström BM, Lindskog C, Oksvold P, Mardinoglu A, Sivertsson Å, Kampf C, Sjöstedt E, Asplund A, et al: Proteomics. Tissue-based map of the human proteome. Science 347: 1260419, 2015.

57. Nagaraj N, Wisniewski JR, Geiger T, Cox J, Kircher M, Kelso J, Pääbo S and Mann M: Deep proteome and transcriptome mapping of a human cancer cell line. Mol Syst Biol 7: 548, 2011.

58. Geyer PE, Kulak NA, Pichler G, Holdt LM, Teupser D and Mann M: Plasma proteome profiling to assess human health and disease. Cell Syst 2: 185-195, 2016

59. Nättinen J, Jylhä A, Aapola U, Mäkinen P, Beuerman R, Pietilä J, Vaajanen A and Uusitalo H: Age-associated changes in human tear proteome. Clin Proteomics 16: 11, 2019.

60. Gilar M and Neue UD: Peak capacity in gradient reversed-phase liquid chromatography of biopolymers. Theoretical and practical implications for the separation of oligonucleotides. J Chromatogr A 1169: 139-150, 2007.

61. Shen Y, Zhao R, Belov ME, Conrads TP, Anderson GA, Tang K, Pasa-Tolić L, Veenstra TD, Lipton MS, Udseth HR and Smith RD: Packed capillary reversed-phase liquid chromatography with high-performance electrospray ionization Fourier transform ion cyclotron resonance mass spectrometry for proteomics. Anal Chem 73: 1766-1775, 2001.

62. Hsieh EJ, Bereman MS, Durand S, Valaskovic GA and MacCoss MJ: Effects of column and gradient lengths on peak capacity and peptide identification in nanoflow LC-MS/MS of complex proteomic samples. J Am Soc Mass Spectrom 24: 148-153, 2013.

63. Doerr A: Mass spectrometry-based targeted proteomics. Nat Methods 10: 23, 2013

64. Carapito C and Aebersold R: Targeted proteomics. Proteomics 12: 1073, 2012

65. Borrebaeck CA: Precision diagnostics: Moving towards protein biomarker signatures of clinical utility in cancer. Nat Rev Cancer 17: 199-204, 2017

66. Zhang Z: An in vitro diagnostic multivariate index assay (IVDMIA) for ovarian cancer: Harvesting the power of multiple biomarkers. Rev Obstet Gynecol 5: 35-41, 2012.

67. Ueland FR, Desimone CP, Seamon LG, Miller RA, Goodrich S, Podzielinski I, Sokoll L, Smith A, van Nagell JR Jr and Zhang Z: Effectiveness of a multivariate index assay in the preoperative assessment of ovarian tumors. Obstet Gynecol 117: 1289-1297, 2011.

68. Janssen PT and van Bijsterveld OP: Origin and biosynthesis of human tear fluid proteins. Invest Ophthalmol Vis Sci 24 623-630, 1983.

69. Tsai PS, Evans JE, Green KM, Sullivan RM, Schaumberg DA, Richards SM, Dana MR and Sullivan DA: Proteomic analysis of human meibomian gland secretions. Br J Ophthalmol 90: 372-377, 2006

70. Gipson IK: Goblet cells of the conjunctiva: A review of recent findings. Prog Retin Eye Res 54: 49-63, 2016.

71. de Souza GA, Godoy LM and Mann M: Identification of 491 proteins in the tear fluid proteome reveals a large number of proteases and protease inhibitors. Genome Biol 7: R72, 2006

72. Ananthi S, Santhosh RS, Nila MV, Prajna NV, Lalitha P and Dharmalingam K: Comparative proteomics of human male and female tears by two-dimensional electrophoresis. Exp Eye Res 92: 454-463, 2011. 
73. Seamon V, Vellala K, Zylberberg C, Ponamareva O and Azzarolo AM: Sex hormone regulation of tear lipocalin in the rabbit lacrimal gland. Exp Eye Res 87: 184-190, 2008.

74. Tong L, Zhou XY, Jylha A, Aapola U, Liu DN, Koh SK, Tian D, Quah J, Uusitalo H, Beuerman RW and Zhou L: Quantitation of 47 human tear proteins using high resolution multiple reaction monitoring (HR-MRM) based-mass spectrometry. J Proteomics 115: 36-48, 2015.

75. Aass C, Norheim I, Eriksen EF, Thorsby PM and Pepaj M: Single unit filter-aided method for fast proteomic analysis of tear fluid. Anal Biochem 480: 1-5, 2015.

76. Zubarev RA and Makarov A: Orbitrap mass spectrometry. Anal Chem 85: 5288-5296, 2013.

77. Perry RH, Cooks RG and Noll RJ: Orbitrap mass spectrometry: Instrumentation, ion motion and applications. Mass Spectrom Rev 27: 661-699, 2008.

78. Dor M, Eperon S, Lalive PH, Guex-Crosier Y, Hamedani M, Salvisberg C and Turck N: Investigation of the global protein content from healthy human tears. Exp Eye Res 179: 64-74, 2019

79. Shamsi FA, Chen Z, Liang J, Li K, Al-Rajhi AA, Chaudhry IA, $\mathrm{Li} \mathrm{M}$ and Wu K: Analysis and comparison of proteomic profiles of tear fluid from human, cow, sheep, and camel eyes. Invest Ophthalmol Vis Sci 52: 9156-9165, 2011.

80. The definition and classification of dry eye disease: Report of the definition and classification subcommittee of the international dry eye WorkShop (2007). Ocul Surf 5: 75-92, 2007.

81. Craig JP, Nichols KK, Akpek EK, Caffery B, Dua HS, Joo CK Liu Z, Nelson JD, Nichols JJ, Tsubota K and Stapleton F: TFOS DEWS II definition and classification report. Ocul Surf 15: 276-283, 2017

82. Shimazaki J: Definition and diagnostic criteria of dry eye disease: Historical overview and future directions. Invest Ophthalmol Vis Sci 59: DES7-DES12, 2018.

83. Abelson MB, Ousler GW III, Nally LA, Welch D and Krenzer K: Alternative reference values for tear film break up time in normal and dry eye populations. Adv Exp Med Biol 506 1121-1125, 2002.

84. Senchyna M and Wax MB: Quantitative assessment of tear production: A review of methods and utility in dry eye drug discovery. J Ocul Biol Dis Infor 1: 1-6, 2008.

85. Nichols KK, Mitchell GL and Zadnik K: The repeatability of clinical measurements of dry eye. Cornea 23: 272-285, 2004.

86. Huang JF, Zhang Y, Rittenhouse KD, Pickering EH and McDowell MT: Evaluations of tear protein markers in dry eye disease: Repeatability of measurement and correlation with disease. Invest Ophthalmol Vis Sci 53: 4556-4564, 2012.

87. Zhou L, Beuerman RW, Chan CM, Zhao SZ, Li XR, Yang H, Tong L, Liu S, Stern ME and Tan D: Identification of tear fluid biomarkers in dry eye syndrome using iTRAQ quantitative proteomics. J Proteome Res 8: 4889-4905, 2009.

88. Ryckman C, Vandal K, Rouleau P, Talbot M and Tessier PA: Proinflammatory activities of S100: Proteins S100A8, S100A9, and S100A8/A9 induce neutrophil chemotaxis and adhesion. J Immunol 170: 3233-3242, 2003.

89. Danjo Y, Lee M, Horimoto K and Hamano T: Ocular surface damage and tear lactoferrin in dry eye syndrome. Acta Ophthalmol (Copenh) 72: 433-437, 1994

90. Breustedt DA, Schönfeld DL and Skerra A: Comparative ligand-binding analysis of ten human lipocalins. Biochim Biophys Acta 1764: 161-173, 2006.

91. Tong L, Zhou L, Beuerman RW, Zhao SZ and Li XR: Association of tear proteins with meibomian gland disease and dry eye symptoms. Br J Ophthalmol 95: 848-852, 2011.

92. Foell D, Wittkowski H, Ren Z, Turton J, Pang G, Daebritz J, Ehrchen J, Heidemann J, Borody T, Roth J and Clancy R: Phagocyte-specific S100 proteins are released from affected mucosa and promote immune responses during inflammatory bowel disease. J Pathol 216: 183-192, 2008.

93. Versura P, Nanni P, Bavelloni A, Blalock WL, Piazzi M, Roda A and Campos EC: Tear proteomics in evaporative dry eye disease. Eye (Lond) 24: 1396-1402, 2010.

94. Fukuda M, Fullard RJ, Willcox MD, Baleriola-Lucas C, Bestawros F, Sweeney D and Holden BA: Fibronectin in the tear film. Invest Ophthalmol Vis Sci 37: 459-467, 1996.

95. Perumal N, Funke S, Pfeiffer N and Grus FH: Proteomics analysis of human tears from aqueous-deficient and evaporative dry eye patients. Sci Rep 6: 29629, 2016.

96. Ligtenberg AJ, Veerman EC, Nieuw Amerongen AV and Mollenhauer J: Salivary agglutinin/glycoprotein-340/DMBT1: A single molecule with variable composition and with different functions in infection, inflammation and cancer. Biol Chem 388 : $1275-1289,2007$.
97. Boucher Y, Braud A, Dufour E, Agbo-Godeau S, Baaroun V, Descroix V, Guinnepain MT, Ungeheuer MN, Ottone C and Rougeot C: Opiorphin levels in fluids of burning mouth syndrome patients: A case-control study. Clin Oral Investig 21: 2157-2164, 2017

98. Pappa A, Chen C, Koutalos Y, Townsend AJ and Vasiliou V: Aldh3a1 protects human corneal epithelial cells from ultraviolet- and 4-hydroxy-2-nonenal-induced oxidative damage. Free Radic Biol Med 34: 1178-1189, 2003.

99. Soria J, Acera A, Merayo-LLoves J, Durán JA, González N, Rodriguez S, Bistolas N, Schumacher S, Bier FF, Peter H, et al: Tear proteome analysis in ocular surface diseases using label-free LC-MS/MS and multiplexed-microarray biomarker validation. Sci Rep 7: 17478, 2017.

100. Messmer EM, von Lindenfels V, Garbe A and Kampik A: Matrix metalloproteinase 9 testing in dry eye disease using a commercially available point-of-care immunoassay. Ophthalmology 123 : 2300-2308, 2016

101. Jonsson R, Vogelsang P, Volchenkov R, Espinosa A, Wahren-Herlenius $M$ and Appel S: The complexity of Sjogren's syndrome: Novel aspects on pathogenesis. Immunol Lett 141: $1-9,2011$

102. Kuo MT, Fang PC, Chao TL, Chen A, Lai YH, Huang YT and Tseng CY: Tear proteomics approach to monitoring sjogren syndrome or dry eye disease. Int J Mol Sci 20: 1932, 2019

103. Aqrawi LA, Galtung HK, Vestad B, Øvsteb $\varnothing$ R, Thiede B, Rusthen S, Young A, Guerreiro EM, Utheim TP, Chen X, et al: Identification of potential saliva and tear biomarkers in primary Sjögren's syndrome, utilising the extraction of extracellular vesicles and proteomics analysis. Arthritis Res Ther 19: 14, 2017.

104. Aqrawi LA, Galtung HK, Guerreiro EM, Øvsteb $\varnothing$ R, Thiede B, Utheim TP, Chen X, Utheim ØA, Palm Ø, Skarstein K and Jensen JL: Proteomic and histopathological characterisation of sicca subjects and primary Sjögren's syndrome patients reveals promising tear, saliva and extracellular vesicle disease biomarkers. Arthritis Res Ther 21: 181, 2019.

105. Wong TT, Zhou L, Li J, Tong L, Zhao SZ, Li XR, Yu SJ, Koh SK and Beuerman RW: Proteomic profiling of inflammatory signaling molecules in the tears of patients on chronic glaucoma medication. Invest Ophthalmol Vis Sci 52: 7385-7391, 2011.

106. Csősz É, Deák E, Kalló G, Csutak A and Tőzsér J: Diabetic retinopathy: Proteomic approaches to help the differential diagnosis and to understand the underlying molecular mechanisms. J Proteomics 150: 351-358, 2017.

107. Csősz É, Boross P, Csutak A, Berta A, Tóth F, Póliska S, Török Z and Tózsér J: Quantitative analysis of proteins in the tear fluid of patients with diabetic retinopathy. J Proteomics 75: 2196-2204, 2012.

108. Zhou X, Qu J, Xie R, Wang R, Jiang L, Zhao H, Wen J and Lu F: Normal development of refractive state and ocular dimensions in guinea pigs. Vision Res 46: 2815-2823, 2006.

109. Bartalena L and Fatourechi V: Extrathyroidal manifestations of Graves' disease: A 2014 update. J Endocrinol Invest 37: 691-700, 2014.

110. Lehmann GM, Garcia-Bates TM, Smith TJ, Feldon SE and Phipps RP: Regulation of lymphocyte function by PPARgamma: Relevance to thyroid eye disease-related inflammation. PPAR Res 2008: 895901, 2008.

111. Mourits MP, Prummel MF, Wiersinga WM and Koornneef L: Clinical activity score as a guide in the management of patients with Graves' ophthalmopathy. Clin Endocrinol (Oxf) 47: 9-14, 1997.

112. Turck N, Eperon S, De Los Angeles Gracia M, Obéric A and Hamédani M: Thyroid-associated orbitopathy and biomarkers: Where we are and what we can hope for the future. Dis Markers 2018: 7010196, 2018.

113. Chelala E, El Rami H, Dirani A, Fakhoury H and Fadlallah A Extensive superior limbic keratoconjunctivitis in Graves disease: Case report and mini-review of the literature. Clin Ophthalmol 9: 467-468, 2015.

114. Matheis N, Okrojek R, Grus FH and Kahaly GJ: Proteomics of tear fluid in thyroid-associated orbitopathy. Thyroid 22: 1039-1045, 2012.

115. Torsteinsdóttir I, Hâkansson L, Hällgren R, Gudbjörnsson B Arvidson NG and Venge P: Serum lysozyme: A potential marker of monocyte/macrophage activity in rheumatoid arthritis. Rheumatology (Oxford) 38: 1249-1254, 1999.

116. Barrett AJ: The cystatins: Small protein inhibitors of cysteine proteinases. Prog Clin Biol Res 180: 105-116, 1985

117. Matheis N, Grus FH, Breitenfeld M, Knych I, Funke S, Pitz S, Ponto KA, Pfeiffer N and Kahaly GJ: Proteomics differentiate between thyroid-associated orbitopathy and dry eye syndrome. Invest Ophthalmol Vis Sci 56: 2649-2656, 2015. 
118. Wiesner J and Vilcinskas A: Antimicrobial peptides: The ancient arm of the human immune system. Virulence 1: 440-464, 2010.

119. Ozyildirim AM, Wistow GJ, Gao J, Wang J, Dickinson DP, Frierson HF Jr and Laurie GW: The lacrimal gland transcriptome is an unusually rich source of rare and poorly characterized gene transcripts. Invest Ophthalmol Vis Sci 46: 1572-1580, 2005.

120. Barka T, Asbell PA, van der Noen H and Prasad A: Cystatins in human tear fluid. Curr Eye Res 10: 25-34, 1991.

121. Turcu AF, Kumar S, Neumann S, Coenen M, Iyer S, Chiriboga P, Gershengorn MC and Bahn RS: A small molecule antagonist inhibits thyrotropin receptor antibody-induced orbital fibroblast functions involved in the pathogenesis of Graves ophthalmopathy. J Clin Endocrinol Metab 98: 2153-2159, 2013.

122. Aass C, Norheim I, Eriksen EF, Børnick EC, Thorsby PM and Pepaj M: Comparative proteomic analysis of tear fluid in Graves' disease with and without orbitopathy. Clin Endocrinol (Oxf) 85: 805-812, 2016.

123. McIntosh RS, Cade JE, Al-Abed M, Shanmuganathan V, Gupta R, Bhan A, Tighe PJ and Dua HS: The spectrum of antimicrobial peptide expression at the ocular surface. Invest Ophthalmol Vis Sci 46: 1379-1385, 2005.

124. Wei YH, Chen WL, Hu FR and Liao SL: In vivo confocal microscopy of bulbar conjunctiva in patients with Graves' ophthalmopathy. J Formos Med Assoc 114: 965-972, 2015.

125. Kishazi E, Dor M, Eperon S, Oberic A, Hamedani M and Turck N: Thyroid-associated orbitopathy and tears: A proteomics study. J Proteomics 170: 110-116, 2018.

126. Paraoan L, Grierson I and Maden BE: Analysis of expressed sequence tags of retinal pigment epithelium: Cystatin $\mathrm{C}$ is an abundant transcript. Int J Biochem Cell Biol 32: 417-426, 2000.

127. Yoshida A, Hsu LC and Dave V: Retinal oxidation activity and biological role of human cytosolic aldehyde dehydrogenase. Enzyme 46: 239-244, 1992.

128. Sahu B and Maeda A: Retinol dehydrogenases regulate vitamin A metabolism for visual function. Nutrients 8: 746, 2016.

129. Weinreb RN, Aung T and Medeiros FA: The pathophysiology and treatment of glaucoma: A review. JAMA 311: 1901-1911, 2014.
130. Bourne RR, Taylor HR, Flaxman SR, Keeffe J, Leasher J, Naidoo K, Pesudovs K, White RA, Wong TY, Resnikoff S, et al: Number of people blind or visually impaired by glaucoma worldwide and in world regions 1990-2010: A meta-analysis. PLoS One 11: e0162229, 2016.

131. Harwerth RS and Quigley HA: Visual field defects and retinal ganglion cell losses in patients with glaucoma. Arch Ophthalmol 124: 853-859, 2006 .

132. Rahmani B, Tielsch JM, Katz J, Gottsch J, Quigley H, Javitt J and Sommer A: The cause-specific prevalence of visual impairment in an urban population. The baltimore eye survey. Ophthalmology 103: 1721-1726, 1996.

133. Braunger BM, Fuchshofer R and Tamm ER: The aqueous humor outflow pathways in glaucoma: A unifying concept of disease mechanisms and causative treatment. Eur J Pharm Biopharm 95: 173-181, 2015.

134. Elhawy E, Kamthan G, Dong CQ and Danias J: Pseudoexfoliation syndrome, a systemic disorder with ocular manifestations. Hum Genomics 6: 22, 2012.

135. Weinreb RN, Leung CK, Crowston JG, Medeiros FA, Friedman DS, Wiggs JL and Martin KR: Primary open-angle glaucoma. Nat Rev Dis Primers 2: 16067, 2016.

136. Pieragostino D, Bucci S, Agnifili L, Fasanella V, D'Aguanno S, Mastropasqua A, Ciancaglini M, Mastropasqua L, Di Ilio C, Sacchetta $\mathrm{P}$, et al: Differential protein expression in tears of patients with primary open angle and pseudoexfoliative glaucoma. Mol Biosyst 8: 1017-1028, 2012.

137. Pieragostino D, Agnifili L, Fasanella V, D'Aguanno S, Mastropasqua R, Di Ilio C, Sacchetta P,Urbani A and Del Boccio P: Shotgun proteomics reveals specific modulated protein patterns in tears of patients with primary open angle glaucoma naïve to therapy. Mol Biosyst 9: 1108-1116, 2013.

c) (i) $\ominus$ This work is licensed under a Creative Commons Attribution-NonCommercial-NoDerivatives 4.0 International (CC BY-NC-ND 4.0) License. 